\title{
HycycleS: a project on nuclear and solar hydrogen production by sulphur-based thermochemical cycles
}

\author{
M. Roeb*, D. Thomey, D. Graf and C. Sattler \\ Deutsches Zentrum für Luft- und Raumfahrt, \\ e.V., Solar Research, Linder Höhe, 51147 Köln, Germany \\ E-mail: Martin.Roeb@dlr.de \\ E-mail: dennis.thomey@dlr.de \\ E-mail: daniela.graf@dlr.de \\ E-mail: christian.sattler@dlr.de \\ *Corresponding author
}

\section{S. Poitou, F. Pra, P. Tochon, C. Mansilla, J-C. Robin and F. Le Naour}

\author{
Commissariat à L'Énergie Atomique (CEA), \\ DRT/LITEN/DTS/LETh-GRETh, \\ 17 rue des Martyrs, 38054 Grenoble cedex, France \\ E-mail: sabine.poitou@cea.fr \\ E-mail: franck.pra@cea.fr \\ E-mail: patrice.tochon@cea.fr \\ E-mail: christine.mansilla@cea.fr \\ E-mail: jean-charles.robin@cea.fr \\ E-mail: francois.lenaour@cea.fr
} \author{
University of Sheffield, \\ Mappin Street, Sheffield, S1 3JD, UK \\ E-mail: r.w.k.allen@ sheffield.ac.uk \\ E-mail: r.elder@sheffield.ac.uk \\ E-mail: i.atkin@sheffield.ac.uk
}

R.W.K. Allen, R. Elder and I. Atkin

Department of Chemical and Biological Engineering,

\section{G. Karagiannakis, C. Agrafiotis and} A.G. Konstandopoulos

\author{
Aerosol and Particle Technology Laboratory, \\ Center for Research and Technology, \\ Hellas/Chemical Process Engineering Research Institute, \\ 6th km. Charilaou-Thermi Road, \\ 57001 Thermi Thessaloniki, Greece \\ E-mail: gkarag@cperi.certh.gr \\ E-mail: chrisagr@cperi.certh.gr \\ E-mail: agk@cperi.certh.gr
}




\section{Musella and P. Haehner}

European Commission, JRC - Institute for Energy (SFNR),

Westerduinweg 3, 1755 LE Petten, Netherlands

E-mail: Manuela.musella@jrc.nl

E-mail: peter.haehner@jrc.nl

\section{A. Giaconia, S. Sau and P. Tarquini}

Ente per le Nuove tecnologie, l'Energia e l'Ambiente (ENEA) - Casaccia, Via Anguillarese 301, $00060 \mathrm{~S}$. Maria di Galeria (Roma), Italy

E-mail: alberto.giaconia@casaccia.enea.it

E-mail: salvatore.sau@casaccia.enea.it

E-mail: tarquini@casaccia.enea.it

\section{S. Haussener and A. Steinfeld}

Eidgenoessische Technische Hochschule Zürich, Institut für Energietechnik,

ML J 42.1. Sonneggstrasse 3, 8092 Zürich, Switzerland

E-mail: hsophia@ethz.ch

E-mail: aldo.steinfeld@ethz.ch

\section{S. Martinez, I. Canadas and A. Orden}

Empresarios Agrupados A.I.E.,

Magallanes 3, 28015 Madrid, Spain

E-mail: icm@empre.es

E-mail: sfm@empre.es

E-mail: aom@empre.es

\section{Ferrato}

BOOSTEC S.A.,

Zone Industrielle,

65460 Bazet, France

E-mail: mferrato@boostec.com

\section{J. Hinkley}

CSIRO - Energy Technology,

10 Murray Dwyer Circuit, Steel River Industrial Park,

Mayfield West, NSW 2304, Australia

E-mail: jim.Hinkley@csiro.au 


\title{
E. Lahoda
}

Westinghouse Electric Company, Suite 678, 600 Cranberry Woods Drive 418d, Cranberry Township, PA 16066, USA

E-mail: lahodaej@westinghouse.com

\section{B. Wong}

Inertial Fusion Technology, General Atomics 22T-115, 3550 General Atomics Ct., San Diego, CA 92121, USA

E-mail:wongb@fusion.gat.com

\begin{abstract}
The European FP7 project HycycleS focuses on providing detailed solutions for the design of specific key components for sulphur-based thermochemical cycles for hydrogen production. The key components necessary for the high temperature part of those processes, the thermal decomposition of $\mathrm{H}_{2} \mathrm{SO}_{4}$, are a compact heat exchanger for $\mathrm{SO}_{3}$ decomposition for operation by solar and nuclear heat, a receiver-reactor for solar $\mathrm{H}_{2} \mathrm{SO}_{4}$ decomposition, and membranes as product separator and as promoter of the $\mathrm{SO}_{3}$ decomposition. Silicon carbide has been identified as the preferred construction material. Its stability is tested at high temperature and in a highly corrosive atmosphere. Another focus is catalyst materials for the reduction of $\mathrm{SO}_{3}$. Requirement specifications were set up as basis for design and sizing of the intended prototypes. Rigs for corrosion tests, catalyst tests and selectivity of separation membranes have been designed, built and completed. Prototypes of the mentioned components have been designed and tested.
\end{abstract}

Keywords: sulphur; catalyst; silicon carbide; membranes; thermochemical cycle.

Reference to this paper should be made as follows: Roeb, M., Thomey, D., Graf, D., Sattler, C., Poitou, S., Pra, F., Tochon, P., Mansilla, C., Robin, J-C., Le Naour, F., Allen, R.W.K., Elder, R., Atkin, I., Karagiannakis, G., Agrafiotis, C., Konstandopoulos, A.G., Musella, M., Haehner, P., Giaconia, A., Sau, S., Tarquini, P., Haussener, S., Steinfeld, A., Martinez, S., Canadas, I., Orden, A., Ferrato, M., Hinkley, J., Lahoda, E. and Wong, B. (2011) 'HycycleS: a project on nuclear and solar hydrogen production by sulphur-based thermochemical cycles', Int. J. Nuclear Hydrogen Production and Applications, Vol. 2, No. 3, pp.202-226.

Biographical notes: Martin Roeb holds a degree in Chemistry and received his Doctor degree in Physical Chemistry at the University of Cologne 1997. Since 1998 he has been working as a Scientist at the German Aerospace Centre (DLR). He has been a Work Package Leader and responsible for several EU projects and a Project Coordinator of domestic research projects concerning high temperature solar processes. Since January 2008, he has been the Project Coordinator of the European project HycycleS.

Dennis Thomey received a degree in Mechanical Engineering at the University of Aachen in 2008. Since then he has been working as a Scientist at the DLR in the European project HycycleS. 
Daniela Graf received her Diploma in Energy Engineering Management at the University of Applied and Science, Leipzig. Since 2005, she has been working at the DLR in the field of solar material conversion. More precisely, she is concerned with the technical and economic evaluation of solar-driven hydrogen production processes using thermo-chemical cycles.

Christian Sattler graduated in Chemistry at the University of Bonn, Germany in 1993. In 1997 he received the Doctoral degree in the field of Heterocyclic Chemistry from the Faculty of Mathematics and Natural Sciences of the University of Bonn. Since 1997 he has worked with the DLR. Since 2002, he has been responsible for the Solar Materials Conversion Research Area. Solar hydrogen production and solar chemistry are his main scientific interests.

Sabine Poitou studied Chemical Engineering at ENSIC (Ecole Nationale Supérieure des Industries Chimiques) in the National Polytechnic Institute of Lorraine (1991-1994). Working at the CEA since 1998 as Research Engineer, she was involved on nuclear waste treatment and conditioning studies until 2007. Since 2008, her activity has concentrated on industrial development of hydrogen production with nuclear reactor coupled processes.

Franck Pra is an Engineer in Fluid Mechanics. Since 2001, he has been working as a Scientist at the CEA. He has been a Work Package Leader in several EU projects in Energy. Since 2007, he is involved in the development of solar receiver and high temperature heat exchangers at the CEA.

Patrice Tochon is an Engineer in Fluid Mechanics and received his Doctoral degree in Mechanics at the University of Grenoble 1997. Since 1998, he has been working as a Scientist at the CEA. He has been the Project Coordinator and a Work Package Leader in several EU projects in Energy. Since January 2009 he has been the Head of Laboratory for Thermal Systems and Solar Energy in CEA.

Christine Mansilla received her Masters degree in Energy Science and $\mathrm{PhD}$ in Industrial Engineering at the Ecole Centrale de Paris in 2006. Since then, she has been working as a Research Engineer at the CEA, especially in techno-economics for the evaluation of the production cost of advanced hydrogen processes.

Jean-Charles Robin worked for several years as a Researcher, Project Manager and Programme Manger at CEA. Since 2009, he has been working at OECD with a focus on nuclear and solar hydrogen production.

Francois LeNaour has been working for CEA in different positions over the last ten years. At the time being, he is a Programme Manager and responsible for hydrogen production.

Ray Allen is a Professor of Chemical Engineering at the University of Sheffield. UK. He has been involved in European and UK funded research in thermochemical cycles since 2003 .

Rachael Elder received her Masters degree in Chemical Engineering from Cambridge University and completed her $\mathrm{PhD}$, also in Chemical Engineering, at the University of Sheffield in 2007. Since then she has worked as a Research Associate and is now a Lecturer at the University of Sheffield. During her PhD she worked on the EU HYTHEC project and is now involved in the HycycleS project. 
Ian Atkin obtained his Masters degree in Chemical Engineering from the University of Sheffield in 2005 and has just submitted his PhD thesis. The work for his doctorate was part of the EU HycycleS project.

George Karagiannakis received his $\mathrm{PhD}$ in Chem. Eng., at the Aristotle Univ. of Thessaloniki, Greece. He has been an Affiliated Researcher at APTL since 2006 and a member of the Nanoparticles and Catalysts Group. He has expertise in catalytic and electrocatalytic studies, with emphasis in those involving hydrogen productions. He has participated in several national and EU research projects.

Christos Agrafiotis is a Principal Researcher at CPERI, Chemical Engineer. He received his PhD in Chem. Eng., from SUNY, Buffalo, USA. He has more than 15 years of expertise in powder synthesis and catalytic coating of monolithic reactors, participated in several EU- and nationally-funded research projects in these areas, and he is the author of more than 40 relevant publications in international journals and proceedings.

Athanasios Konstandopoulos is the Director of APTL and CPERI and 2006 Descartes Laureate. $\mathrm{He}$ is a Specialist in combustion aerosols and nanoparticles, with extensive research and engineering consulting experience. He has managed more than 50 large international projects, including many EU projects in the area of nanoparticle emissions. He is the author of more than 100 scientific and technical papers and a Fellow of the Society of Automotive Engineers (SAE). He has a hybrid background in mechanical and chemical engineering.

Manuela Musella received her $\mathrm{PhD}$ in Mechanical Engineering at the Paul-Scherer-Institute/ETH Zurich in 2005. Since then, she has been working as a Project Engineer for JRC in Petten.

Peter Haehner received his $\mathrm{PhD}$ and University Lecturing Qualification in Physics from the University of Stuttgart and the Technical University of Braunschweig, respectively. In 2000, he joined the Institute for Energy of the European Commission's Joint Research Centre to work as a Senior Scientist in the field of physics and mechanics of structural and functional materials for high temperature applications. Currently he is the Head of the Materials Performance Assessment for Innovative Reactor Systems programme of the institute.

Alberto Giaconia received his $\mathrm{PhD}$ in Chemical Engineering from the University of Palermo in 2000. Since 2004, he has been working as a Researcher at ENEA, with research activity focused on thermochemical hydrogen production by alternative energy sources in the framework of national and international $R \& D$ projects.

Giovanni Salvatore Sau received his degree in Chemistry at the University of Sassari (Italy) in 1994. He has worked in several research fields, especially on instrumental chemical analysis. Since January 2004, he has been involved in the sulphur-iodine process project at the ENEA Centre of Casaccia (Rome, Italy).

Pietro Tarquini graduated in Chemical Engineering from University of Rome in 1977. After experience as a Process Engineer in the Chemical Industry, since 1984 he has been working as a Researcher at ENEA on several EU projects; since 2004, he has been the Project Coordinator of the TEPSI Italian domestic project on hydrogen production by solar thermochemical cycles. 
Sophia Haussener received her MSc ETH in Mechanical Engineering and studied Mechanical Engineering at the Swiss Federal Institute of Technology Zurich $(\mathrm{CH})$ and at University of Colorado at Boulder (USA), with focus on microsystems and renewable energies. She started her $\mathrm{PhD}$ studies at ETH in 2007 in the area of high temperature solar energies.

Aldo Steinfeld has been a Full Professor of Renewable Energy Carriers at the ETH Zurich since 2007. He also leads the Solar Technology Laboratory at the Paul Scherrer Institute, Switzerland. He received his PhD in Mechanical Engineering from the University of Minnesota in 1989. His research programme is aimed at the advancement of the thermal, thermochemical, and electrochemical engineering sciences applied to the field of renewable energy technology.

Silvia Martinez has been working as a Project Engineer in R\&D projects for Empresarios Agrupados until 2009.

Ignacio Cañadas received his degrees in Mechanical Engineering at UNED in 2007 and in Medicine at Complutense University (Orthopaedic Surgery and Traumatology, 2007). Since 2008, he has worked as a Mechanical Engineer at EA. He has participated in several EU projects and other projects concerning mechanical calculations and design, nuclear components specifications and mechanical processes. Since October 2008, he has been working in the European project HycycleS.

Alfredo Orden has been working for Empresarios Agrupados for more than ten years in different fields and positions. Currently, he leads a group focussing on $\mathrm{R} \& \mathrm{D}$ projects in the field of nuclear heat, power and safety issues.

Marc Ferrato received his Doctoral degree in the field of ceramic material science at the University of Limoges in 1994. Since 1994, he has mainly been involved in the field of non-oxide ceramic materials. Since the founding of Boostec in 1999, he has been working on new silicon carbide devices mainly for green technology applications.

Jim Hinkley is a Chemical and Process Engineer. He completed his $\mathrm{PhD}$ in Chemical Engineering at the University of Newcastle in 2003 and has been worked at CSIRO. He assisted with the construction and commissioning of CSIRO's $500 \mathrm{~kW}$ heliostat field, and has been worked on a number of high temperature solar projects for hydrogen production, from methane reforming and thermochemical water splitting cycles.

Edward Lahoda received his BS, MS and $\mathrm{PhD}$ in Chemical Engineering and an MBA from the University of Pittsburgh. He has been working for Westinghouse Electric since 1974 in the chemical process development area. $\mathrm{He}$ is the Head of Westinghouse Electric chemical engineering effort in nuclear generated hydrogen.

Bunsen Wong received his Doctoral degree in Materials Science from Carnegie Mellon University, PA, USA. He has been with General Atomics since 2003 and he is the Project Manager for both the solar hydrogen and the thermal energy storage projects. 


\section{Introduction}

HycycleS is a cooperation of nine European partners and includes also non-European partners which are international players in that area. The project aims at the qualification and enhancement of materials and components for key steps of solar and nuclear powered thermo-chemical cycles for hydrogen generation from water. Therefore the project brings together expects from nuclear, from solar, and from material research. The focus of HycycleS is the decomposition of sulphuric acid which is the central step of the sulphur-based family of those processes, especially the hybrid sulphur cycle (HyS) (Brecher et al., 1976) and the sulphur-iodine cycle (S-I) (Norman et al., 1982). Emphasis is put on materials and components for sulphuric acid evaporation, decomposition, and sulphur dioxide separation. The suitability of materials and the reliability of the components is shown in practice by decomposing sulphuric acid and separating its decomposition products in scalable prototypes.

HycycleS concentrates on providing detailed solutions for the design of specific key components. The key components necessary for the high temperature part of the process and the ones targeted are a compact heat exchanger for $\mathrm{SO}_{3}$ decomposition suitable for operation by solar and nuclear heat, a receiver-reactor for solar $\mathrm{H}_{2} \mathrm{SO}_{4}$ evaporation and $\mathrm{SO}_{3}$ decomposition, and an oxygen separator for $\mathrm{SO}_{2}$ and $\mathrm{O}_{2}$ as product separator and as promoter of the $\mathrm{SO}_{3}$ decomposition.

Among all the possible candidates of materials facing these chemicals at high temperature, silicon carbide $(\mathrm{SiC})$ appears the most suitable for multiple applications. It should be able to function both at high temperature and in a highly corrosive atmosphere for use in a solar absorber or as plates in a heat exchanger. A sufficient reaction rate for the high temperature splitting of sulphur trioxide is also crucial for the sulphuric acid decomposition. This only can be ensured by the use of dedicated catalyst systems. These have to match the main requirements being a high catalytic activity, high stability and immobility of catalyst materials under the harsh conditions applied, and an acceptable price. HycycleS works on advanced solutions for those requirements on the basis of previous results, e.g., of the EU FP6 project HYTHEC (http://www.hythec.org).

The final aim is to bring thermo-chemical water splitting closer to realisation by improving the efficiency, stability, practicability, and costs of the key components involved and by elaborating detailed engineering solutions.

\section{Construction materials and catalysts}

\subsection{Construction materials}

The relevant materials for decomposition of $\mathrm{H}_{2} \mathrm{SO}_{4}$ should maintain appropriate properties for the chemical reaction at temperatures higher than $850^{\circ} \mathrm{C}$. The material must be corrosion resistant and should exhibit high fracture and creep strength. In the case of heat exchangers they need to be gas-tight. The material must be capable of working in a temperature range of $800^{\circ} \mathrm{C}$ to $1,000^{\circ} \mathrm{C}$ for solar operation, perhaps even higher. It has to maintain almost full mechanical strength in this temperature range. The material must be cheap and should be preferably be able to be fabricated in netshape or honeycomb design. It must allow for catalyst or corrosion resistance coating. The material should be thermo-shock resistant due to thermal gradients. Promising material candidates for the 
decomposition section include nickel-based alloys, HT ferrous steels, as well as carbon and $\mathrm{SiC}$ composites (disregarding very expensive noble metals). Studies in the US and Japan (Terada et al., 2006; Lewinsohn et al., 2006; Wong et al., 2007) identified the SiC family as one of the most promising candidates for this application. The SiC family obviously obtains its corrosion stability through the formation of a stable silica layer. Indeed, its exceptional thermal conductivity $\left(170 \mathrm{~W} / \mathrm{m}^{*} \mathrm{~K}\right.$ at room temperature), its refractory nature (stable up to $1,600^{\circ} \mathrm{C}$ under air) and its resistance to corrosive environment make this material a favoured candidate for high temperature heat exchangers. There are different types of $\mathrm{SiC}$ that can be classified by their different fabrication processes, e.g., sintered $\mathrm{SiC}$ without any additives, compressed $\mathrm{SiC}$ at high temperature, and $\mathrm{SiC}$ formed by chemical reaction. Today the most practical $\mathrm{SiC}$ is the sintered $\mathrm{SiC}$ without additives. $\mathrm{SiC}$ pieces can be made by pressing in a matrix, by extrusion at hot temperatures (for tubes), by casting with injection (small pieces with complex geometry). Very large $\mathrm{SiC}$ pieces are formed by machining of pre-designed pieces obtained by cold isostatic compression.

In the European project HYTHEC SiC was selected as the material of choice for a solar absorber being at the same time the decomposer for $\mathrm{H}_{2} \mathrm{SO}_{4}$ in a receiver-reactor (Le Duigou et al., 2007). This is due to the combination of the above mentioned chemical resistance and thermo-mechanical properties plus its excellent optical properties (high absorptivity for radiation). Beyond that HYTHEC detected a significant catalytic activity of siliconised $\mathrm{SiC}$ with regard to the decomposition of sulphur trioxide (Noglik et al., 2007). Based on these results HycycleS will focus on different types of materials of the $\mathrm{SiC}$ family, as well as their brazed joints. By a systematic analysis of the long-term stability in representative corrosive environments the suitability of this material system for use in the heat-exchange/decomposer and the solar heated receiver-reactors is being determined. Moreover, the suitability will be demonstrated by fabricating the described components as prototypes using this material and by testing them under realistic conditions.

The first year of the project began with a review on potential construction materials for the targeted key components of sulphur-based thermo-chemical cycles. As a consequence of this review HycycleS main development route will be based on ceramic materials from the $\mathrm{SiC}$ family - for the solar absorbers of the planned receiver reactor as well as for the plates of the planned compact heat exchanger. Base materials for separation membranes will be YSZ. The first phase of the long term exposure of samples to corrosive environments pertinent to various sections of heat-exchange/decomposer and/or solar receiver decomposer has already been carried out in test rigs like the ones depicted in Figure 1 and Figure 2. So far, the materials and samples seem promising in terms of withstanding the conditions in terms of their general corrosion resistance and their ability to maintain a sufficient degree of high temperature mechanical strength over a substantial period of time.

General Atomics has screened construction materials that are applicable in concentrated phosphoric acid which is one of the corrosive acids used in the extractive distillation process of the S-I. Both coupon and stress corrosion specimens were tested in concentrated boiling phosphoric acid $(85-96 \mathrm{wt} \%)$ between $190^{\circ} \mathrm{C}$ and $230^{\circ} \mathrm{C}$. The work was carried out under the support of the US DOE Nuclear Hydrogen Initiative. Results from long term screening of coupon samples showed that only SiC-based materials and Ta-based alloys have acceptable corrosion rate of less than 5 mpy. Hastelloy B2, C276, $\mathrm{CuNi} \mathrm{C} 706$, mullite, alumina and $\mathrm{Ag}$ alloys all showed high corrosion rates in this 
chemical environment. Preliminary testing of Ta-W c-ring stress corrosion specimens showed cracks developing in some of them. Conditions for crack initiation and propagation are being explored and further stress corrosion testing is planned. Furthermore, the corrosion characteristics of $\mathrm{SiSiC}$ in boiling concentrated phosphoric acid are also being investigated.

Figure 1 Photograph of experimental setup for the corrosion studies at Joint Research Center Petten $\left(\mathrm{SO}_{3}\right.$ reduction) (see online version for colours)

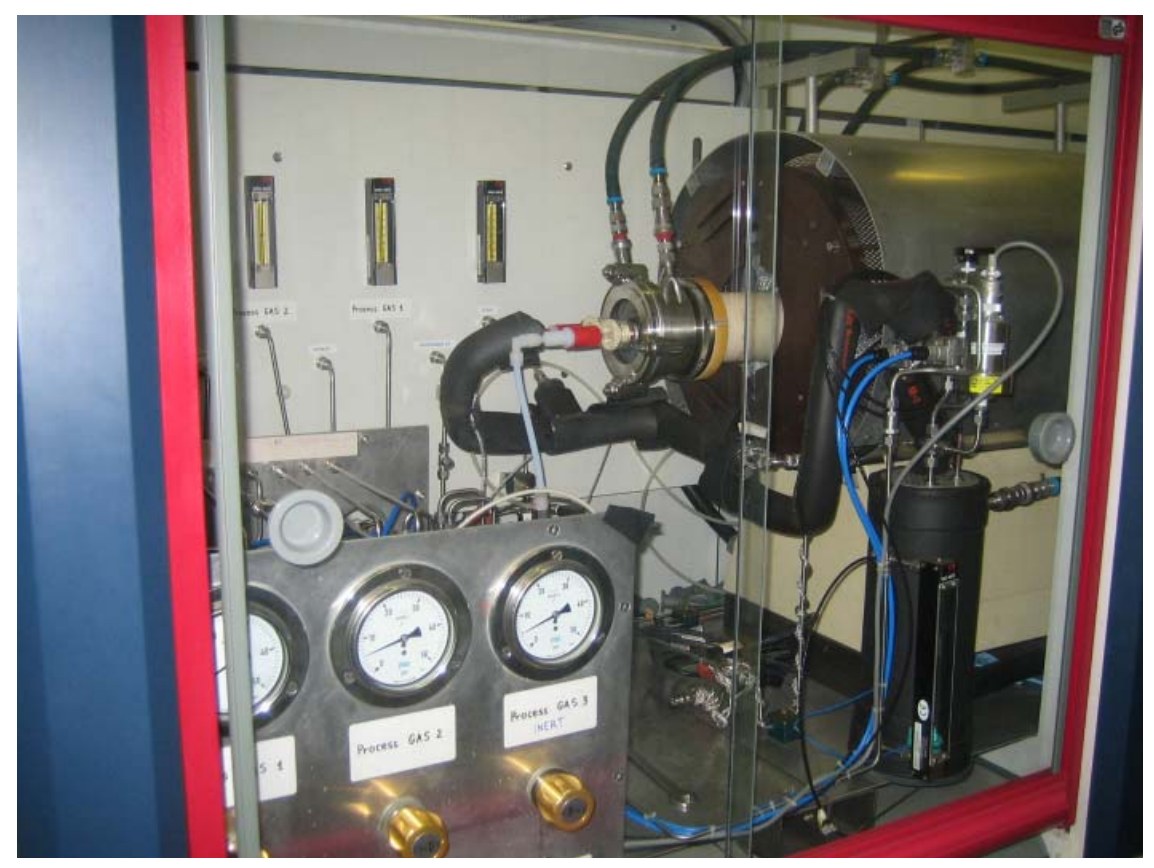

Figure 2 Scheme of experimental setup for the corrosion studies at German Aerospace Center (evaporation of $\mathrm{H}_{2} \mathrm{SO}_{4}$ ) (see online version for colours)

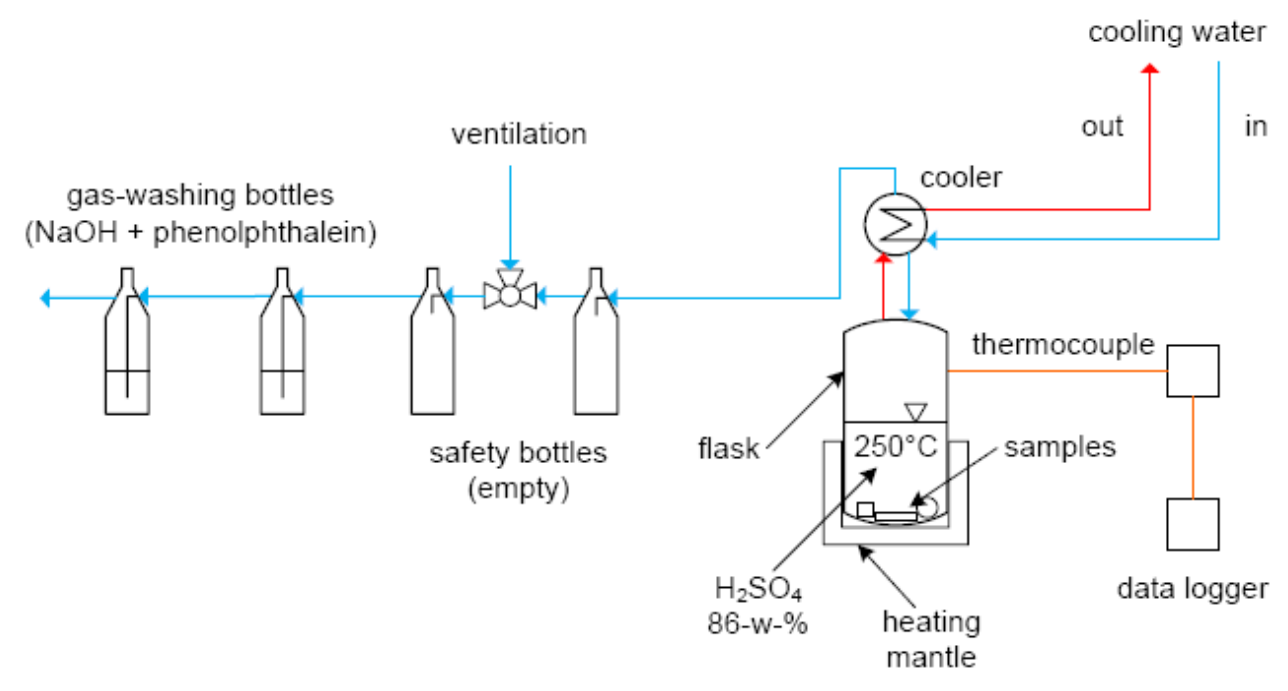




\subsection{Catalysts}

To achieve a higher efficiency of the splitting reaction of $\mathrm{SO}_{3}$ into $\mathrm{SO}_{2}$ at temperatures of about $750^{\circ} \mathrm{C}-900^{\circ} \mathrm{C}$ different catalyst-substrate combinations have been investigated, mainly using noble metals or transition metal oxides (Jung et al., 2006; Barbarossa et al., 2004, 2005, 2006; Brutti et al., 2006; O’Keefe et al., 1980; Ginosar et al., 2007). The activity of the catalyst in most cases increases with the BET area, but the stability decreases. Typically the catalysts were dispersed as nanoparticles on the surface of various ceramic substrates $\left(\mathrm{SiO}_{2}, \mathrm{TiO}_{2}, \mathrm{Al}_{2} \mathrm{O}_{3}\right)$. During long-term testing using catalysts like $\mathrm{Pt}, \mathrm{Pd}, \mathrm{Pt} / \mathrm{Ru}, \mathrm{Pt} / \mathrm{Rh}$ a deactivation of the catalyst was observed in combination with a significant change in particle size. Migration of catalyst was identified as a main reason for the deactivation. Since the decomposition process provides an extremely harsh environment for catalyst stability, highly active long-term catalysts have not yet been identified. Novel approaches involve studies of mixed metal oxides which promise to be more stable at high temperatures. A Korean group proposes metal oxides with spinel structures which appear to be one of the most promising options today (Jung et al., 2006).

The use of porous ceramics and plate heat exchangers made of $\mathrm{SiC}$ means this material may well be suitable as a substrate. HYTHEC has already shown that it is feasible to coat such material with noble metal and iron oxide catalysts exhibiting high and stable activity throughout experimental campaigns (Le Duigou et al., 2007).

HycycleS will build on these results as a starting point to develop and qualify a catalyst-substrate assembly with a high and long-lasting activity. With its broad experience on testing and qualifying different catalyst systems, ENEA will be identifying the most suitable starting point for investigation. Their most recent investigation identified a high potential of the low-cost option of using iron oxide-based materials. Special emphasis is put on the immobilisation of the catalyst though advanced coating techniques. The consortium will make use of the preliminary success with the coating techniques previously applied in HYTHEC. Beyond that HycycleS will combine the Korean results on very stable and active metal oxide spinel catalyst with the results from the EU FP5 project HYDROSOL. APTL and DLR have shown the feasibility of using those for the high-temperature splitting of water. $\mathrm{SiC}$ honeycombs coated by this type of material enabled the hydrogen production for several hours and cycles without significant degradation (Roeb et al., 2006). Suitable coating techniques enabling such stable systems have already been developed and qualified in HYDROSOL by the partner APTL.

In terms of HycycleS experimental studies, a preliminary evaluation of the catalytic activity of various candidate materials was performed. These materials were tested in the form of powders and include commercial iron oxides (i.e., $\mathrm{FeO}, \mathrm{Fe}_{3} \mathrm{O}_{4}$ and $\mathrm{Fe}_{2} \mathrm{O}_{3}$ ), an 'in-house' prepared iron oxide, $\gamma-\mathrm{Al}_{2} \mathrm{O}_{3}$, a $\mathrm{Fe}-\mathrm{Al}$ mixed oxide prepared by the self-propagating high-temperature synthesis (SHS) technique as well as commercial $\mathrm{CuO}$. In addition, a 'blank' experiment (untreated $\gamma-\mathrm{Al}_{2} \mathrm{O}_{3}$ ) was performed while the catalytic activity of $\mathrm{SiSiC}$ was also measured, as this is considered the most suitable catalyst substrate for such an application.

The experiments were conducted with the aid of a customised test rig utilising concentrated (94\%-98\%) sulphuric acid. The reaction conditions were $850^{\circ} \mathrm{C}$ and atmospheric pressure while catalyst loading was 0.5 gr. The Weight Hourly Space Velocity (WHSV), on the basis of liquid $\mathrm{H}_{2} \mathrm{SO}_{4}$ feed flow, was $52 \mathrm{~h}{ }_{-1}$. Each experiment lasted for approximately $45 \mathrm{~min}$. 
The calculated conversion for the 'blank' experiment was $<3 \%$ while $\mathrm{SiSiC}$ yielded a steady state conversion of approx. 5\%. More details regarding the rather interesting transient behaviour of $\mathrm{SiSiC}$ is provided below (see Figure 3 ). The catalytic activity of the materials examined follows the order of: $\mathrm{CuO}>\mathrm{Fe}_{2} \mathrm{O}_{3} \approx \mathrm{Fe}-\mathrm{Al}-\mathrm{O}>\mathrm{Fe}_{3} \mathrm{O}_{4} \approx$ 'inhouse' $\mathrm{FeO}>\mathrm{FeO}>\gamma-\mathrm{Al}_{2} \mathrm{O}_{3}$. In most of the cases, analysis of spent samples by XRD combined with their thermogravimetric analysis (TGA) under air revealed the presence of sulphate species, which provides strong indication that the reaction proceeds via the general scheme of:

$$
\mathrm{MO}+\mathrm{SO}_{3} \rightarrow \mathrm{MSO}_{4} \rightarrow \mathrm{MO}+\mathrm{SO}_{2}+0.5 \mathrm{O}_{2}
$$

Another interesting post-analysis observation is related to the significant loss of all samples initial BET surface area. This is attributed either to sintering or to phase changes related to the 'extreme' reaction environment. Additionally, $\gamma-\mathrm{Al}_{2} \mathrm{O}_{3}$ and $\mathrm{Fe}-\mathrm{Al}-\mathrm{O}$ seem to have undergone aluminium leaching. More specifically, XRD analysis of spent Fe-Al-O revealed that aluminium content was significantly lower while the mass comparison of fresh and spent $\gamma-\mathrm{Al}_{2} \mathrm{O}_{3}$ and $\mathrm{Fe}-\mathrm{Al}-\mathrm{O}$ samples revealed a weight loss of spent ones. In Table 1 a summary of changes observed in the samples after their exposure to reaction conditions is provided.

Table 1 Catalysts properties before and after exposure to reaction conditions

\begin{tabular}{|c|c|c|c|c|c|}
\hline Sample & $\begin{array}{c}\text { BET in } \mathrm{m}^{2} / g r \\
\text { (fresh } \\
\text { sample) }\end{array}$ & $\begin{array}{c}\text { BET in } \mathrm{m}^{2} / g r \\
\text { (spent } \\
\text { sample) }\end{array}$ & $\begin{array}{c}\text { Phases } \\
\text { identified in } \\
\text { fresh sample }\end{array}$ & $\begin{array}{c}\text { Phases } \\
\text { identified in } \\
\text { spent sample }\end{array}$ & Comment \\
\hline$\gamma-\mathrm{Al}_{2} \mathrm{O}_{3}$ & 179 & 117 & $\gamma-\mathrm{Al}_{2} \mathrm{O}_{3}$ & $\begin{array}{c}\gamma-\mathrm{Al}_{2} \mathrm{O}_{3} \text { and } \\
\text { aluminium } \\
\text { sulphate } \\
\text { species }\end{array}$ & $\begin{array}{l}\text { Aluminium } \\
\text { leaching } \\
\text { observed }\end{array}$ \\
\hline $\mathrm{FeO}$ & 1.54 & $<0.2$ & $\mathrm{FeO}$ & $\begin{array}{c}\mathrm{Fe}_{2} \mathrm{O}_{3} \text { and } \\
\text { iron sulphate } \\
\text { species }\end{array}$ & $\begin{array}{l}\text { Sulphates } \\
\text { were } \\
\text { detected by } \\
\text { both XRD } \\
\text { and TGA } \\
\text { (>5\% wt } \\
\text { content) }\end{array}$ \\
\hline $\begin{array}{l}\text { 'In-house' } \\
\mathrm{FeO}\end{array}$ & 0.92 & $<0.4$ & $\begin{array}{c}\mathrm{FeO}, \mathrm{Fe}_{3} \mathrm{O}_{4} \\
\text { and } \mathrm{Fe}\end{array}$ & $\begin{array}{c}\mathrm{Fe}_{2} \mathrm{O}_{3} \text { and } \\
\text { iron sulphate } \\
\text { species }\end{array}$ & \\
\hline $\mathrm{Fe}_{3} \mathrm{O}_{4}$ & 1.47 & 0.98 & $\mathrm{Fe}_{3} \mathrm{O}_{4}$ & $\begin{array}{c}\mathrm{Fe}_{2} \mathrm{O}_{3} \text { and } \\
\text { iron sulphate } \\
\text { species }\end{array}$ & $\begin{array}{c}\text { Sulphates } \\
\text { were } \\
\text { detected by } \\
\text { TGA only } \\
\text { ( }<5 \% \mathrm{wt} \\
\text { content) }\end{array}$ \\
\hline $\mathrm{Fe}_{2} \mathrm{O}_{3}$ & 5.79 & 2.38 & $\mathrm{Fe}_{2} \mathrm{O}_{3}$ & $\mathrm{Fe}_{2} \mathrm{O}_{3}$ & \\
\hline Fe-Al-O & 17.70 & 4.91 & $\begin{array}{c}\text { Fe- } \mathrm{Al} \text { mixed } \\
\text { oxide, } \mathrm{Fe}_{2} \mathrm{O}_{3} \text {, } \\
\mathrm{Fe}_{3} \mathrm{O}_{4}, \mathrm{Fe} \\
\text { and } \mathrm{Al}_{2} \mathrm{O}_{3}\end{array}$ & $\begin{array}{c}\mathrm{Fe}_{2} \mathrm{O}_{3} \text { and } \\
\text { iron sulphate } \\
\text { species }\end{array}$ & $\begin{array}{l}\text { Aluminium } \\
\text { leaching } \\
\text { observed }\end{array}$ \\
\hline $\mathrm{CuO}$ & 0.50 & $<0.20$ & $\mathrm{CuO}$ & $\mathrm{CuO}+\mathrm{Cu}_{2} \mathrm{O}$ & \\
\hline
\end{tabular}


In terms of current activities, more materials (including SHS-synthesised $\mathrm{Cu}-\mathrm{Fe}$, $\mathrm{Cu}-\mathrm{Fe}-\mathrm{Al}$ and $\mathrm{Fe}-\mathrm{Cr}$ mixed oxides) are currently under investigation in an attempt to further improve catalytic activity. The next step will be the coating of most active materials in $\mathrm{SiSiC}$ monoliths in order to collaboratively perform kinetic studies and examine their long-term stability under reaction conditions. A first series of tests were carried out to investigate the catalytic activity of a special SiSiC powder, as shown in Figure 3. After about ten minutes the system reached a stationary outlet composition, with three analysis methods giving approximately the same results, i.e., about $6 \%-8 \%$ $\mathrm{SO}_{3}$ conversion.

It is noticeable that initial $\mathrm{SO}_{2}$ yield measured by using a Bunsen trap reaches quite high values, but rapidly decreases, while the $\mathrm{O}_{2}$ production rate is still low. A possible explanation of this behaviour is the interaction of $\mathrm{SiSiC}$ powder with the $\mathrm{SO}_{3}$ in gas mixture at the high operating temperatures $\left(900^{\circ} \mathrm{C}\right)$, so that $\mathrm{SiSiC}$ gets passivated in the first phase of the tests, thereby acting as a 'getter' for the oxygen when reacting with $\mathrm{SO}_{3}$. The consequence would be that $\mathrm{SO}_{2}$ is formed in this period, which can be analysed by titration of the solution in the Bunsen trap, whereas the accompanying $\mathrm{O}_{2}$ reacts with $\mathrm{SiSiC}$ and can't be detected by GC or oxygen sensor.

The powder material was analysed before and after testing by SEM and EDS analysis. Beside some visible morphological changes like the presence of a more porous and heterogeneous structure, EDS analysis confirmed the presence of regions with higher oxygen concentration, possibly due to oxidation of the precursor material. However, the low conversion values obtained indicate that this specific $\mathrm{SiSiC}$ support material has negligible activity on the $\mathrm{SO}_{3}$ decomposition at $900^{\circ} \mathrm{C}$. The investigation will proceed with the comparison of $\mathrm{SiSiC}$ material from different suppliers.

Figure $3 \mathrm{SO}_{3}$ conversion obtained with $\mathrm{SiSiC}$ powder (see online version for colours)

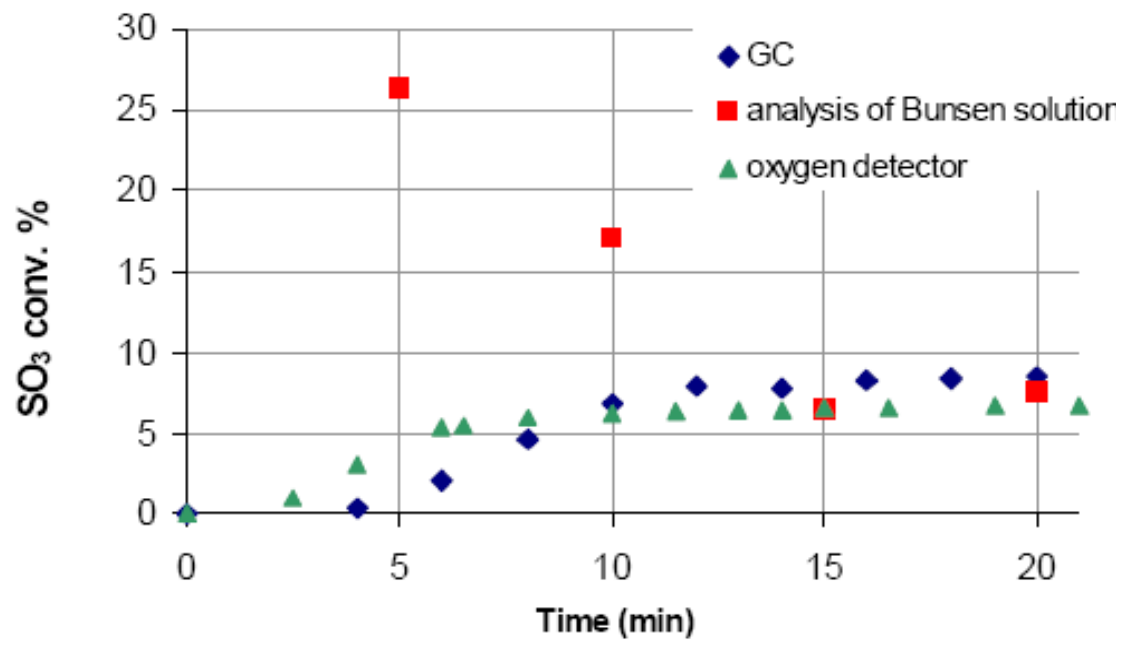

\section{$3 \quad \mathrm{H}_{2} \mathrm{SO}_{4}$ decomposers}

Different concepts to bring in heat into an endothermic chemical process like the decomposition of sulphuric acid have been discussed and comparatively evaluated in past 
by different groups (Gelbard et al., 2005; General Atomics, 1985; Connolly et al., 2007). Those concepts differ with respect to the way of coupling the chemical process to the energy source. For a nuclear heat source, only certain kinds of heat exchangers are in principle suitable for that process step. A solar heat source offers a broader variety of options. In some solar concepts the radiation is directly absorbed by the reactants. In other concepts radiation is absorbed by a surface or wall and transformed into thermal energy, which is transferred by heat conduction to a container with the reactants behind that wall. Other concepts make use of inert heat transfer media which are heated in a receiver and transport the heat to the reactants - directly by mixing or via heat exchangers (tube-and-shell or compact) (Beghi, 1986).

The choice of decomposer concept affects the process design crucially. The project HYTHEC identified two concepts as the most promising for the high temperature decomposition of sulphuric acid: heat exchanger reactor and receiver-reactor. Only the heat-exchanger reactor is possible for a nuclear powered process, whereas a solar powered process can be operated by both technology options.

Table 2 Characteristics of different decomposer technologies

\begin{tabular}{|c|c|c|}
\hline & Heat exchanger reactor & Volumetric receiver reactor \\
\hline Heat source & Nuclear or concentrated solar & Only concentrated solar \\
\hline temperature & $\begin{array}{l}\text { State-of-art: }<900^{\circ} \mathrm{C} \text { due to limitations of } \\
\text { metallic materials; higher T possible by ceramic } \\
\text { HX }\end{array}$ & $\begin{array}{l}\text { Up to } 1,200^{\circ} \mathrm{C} \text { has been } \\
\text { shown possible }\end{array}$ \\
\hline pressure & high, typically more than eight bar & $\begin{array}{l}1-10 \text { bar possible; typically } \\
\text { close to } 1 \text { bar }\end{array}$ \\
\hline \multirow[t]{2}{*}{ medium } & 1 Helium, air... & \multirow{2}{*}{$\begin{array}{l}\text { Only } \mathrm{H}_{2} \mathrm{SO}_{4} \text { and } \\
\text { decomposition products }\end{array}$} \\
\hline & $2 \quad \mathrm{H}_{2} \mathrm{SO}_{4}$ and decomposition products & \\
\hline \multirow[t]{4}{*}{ advantages } & $\begin{array}{l}\text { separation of heat collection and chemical } \\
\text { process }\end{array}$ & $\begin{array}{l}\text { High achievable reaction } \\
\text { temperature } \Rightarrow \text { high yields }\end{array}$ \\
\hline & $\Rightarrow$ Easy controllability of the process & $\begin{array}{l}\text { Less energy conversion steps } \\
\Rightarrow \text { High efficiency of the } \\
\text { decomposition section }\end{array}$ \\
\hline & $\begin{array}{l}\text { Proximity to conventional and mature } \\
\text { technology of heat exchangers }\end{array}$ & $\begin{array}{l}\text { Ambient pressure possible } \\
\Rightarrow \text { 'soft' requirements } \\
\text { regarding pressure resistance } \\
\text { and tightness }\end{array}$ \\
\hline & & $\begin{array}{l}\text { Ambient pressure possible } \\
\Rightarrow \text { high yield }\end{array}$ \\
\hline
\end{tabular}

HYTHEC proved in practice that the concept of a porous absorber reactor as receiver-reactors for solar decomposition of sulphuric acid is feasible (Noglik et al., 2009). Scenarios for scaling up those reactors and the technology have been developed and appear promising. The potential is comparable to the other more independent concept which concerns the use of heat transfer fluids and heat exchanger reactors. Both concepts are worthy of further scrutiny, especially by examining their feasibility in a relevant pilot scale. Characteristics of the two reactor concepts are summarised in Table 2. 


\subsection{Compact heat exchanger as $\mathrm{SO}_{3}$ decomposer}

Three different design options for a $\mathrm{SiC}$ plate heat exchanger have been taken into consideration concerning on the one hand the hot (heat transfer fluid) side and the reaction side of the decomposer on the other hand:

a a wavy pattern on the hot side, dedicated to enhance heat transfer

b a large channel, filled with a fixed bed of catalyst, on the reaction side

c a multiple adiabatic reactor, which separates regions for heat transfer and reactive zones.

From a design point of view, all three concepts are very attractive and will be retained to design and prepare a prototype. However, the plan is first to fabricate small mock-ups for the validation of key aspects of fabrication and process performance, and for the validation of thermal-hydraulic performance.

The multiple adiabatic reactor is regarded as a promising option since it enables the decomposition reaction to be carried out close to the temperature of the coolant and therefore maintain sufficient reaction rates. The reaction mixture alternately passes through catalysts filled reactive zones and heat transfer zones. The endothermic $\mathrm{SO}_{3}$ reduction causes a decrease of fluid temperature. The temperature rises again after heat transfer from the heat transfer fluid providing a saw-tooth-like progression of the temperature as shown in Figure 4. Beyond that the multi adiabatic reactor design allows much easier replacement of catalyst in case of deactivation.

Figure 4 Temperature distribution within the plate reactor (multiple adiabatic bed reactor) (see online version for colours)

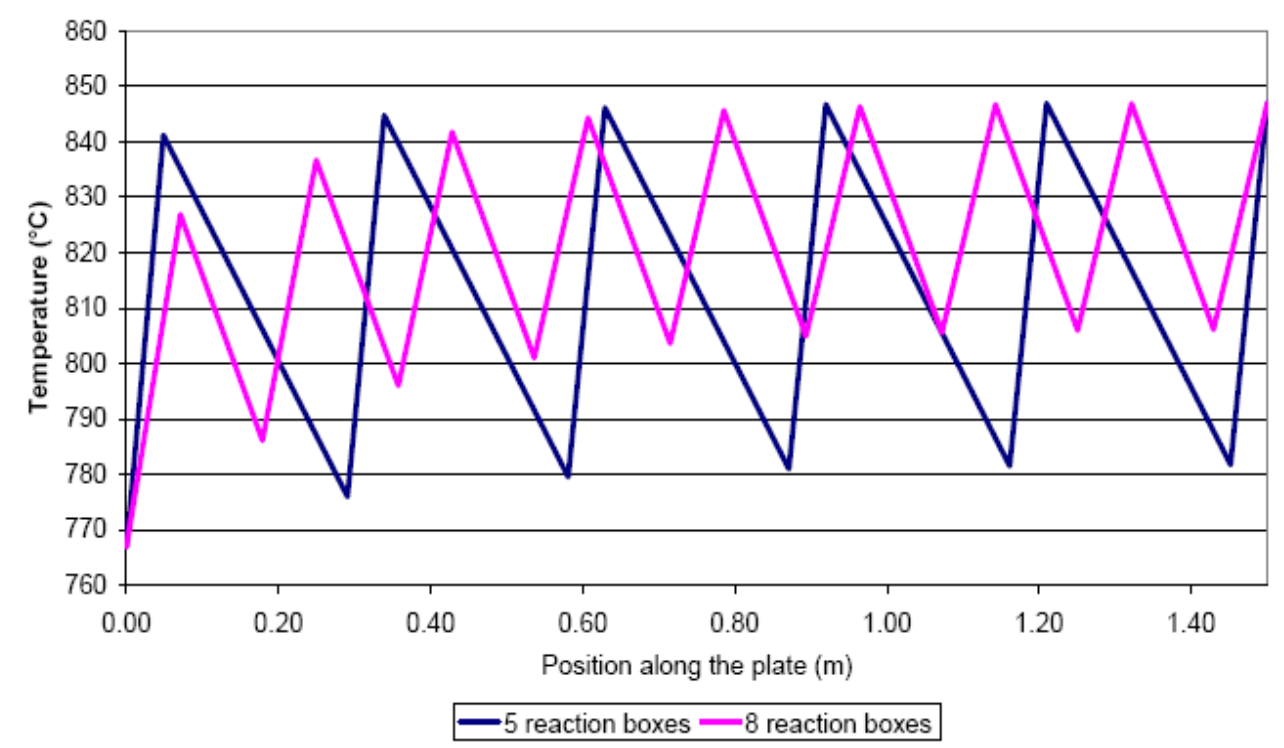


Figure 5 Steps of plate heat exchanger manufacturing (see online version for colours)

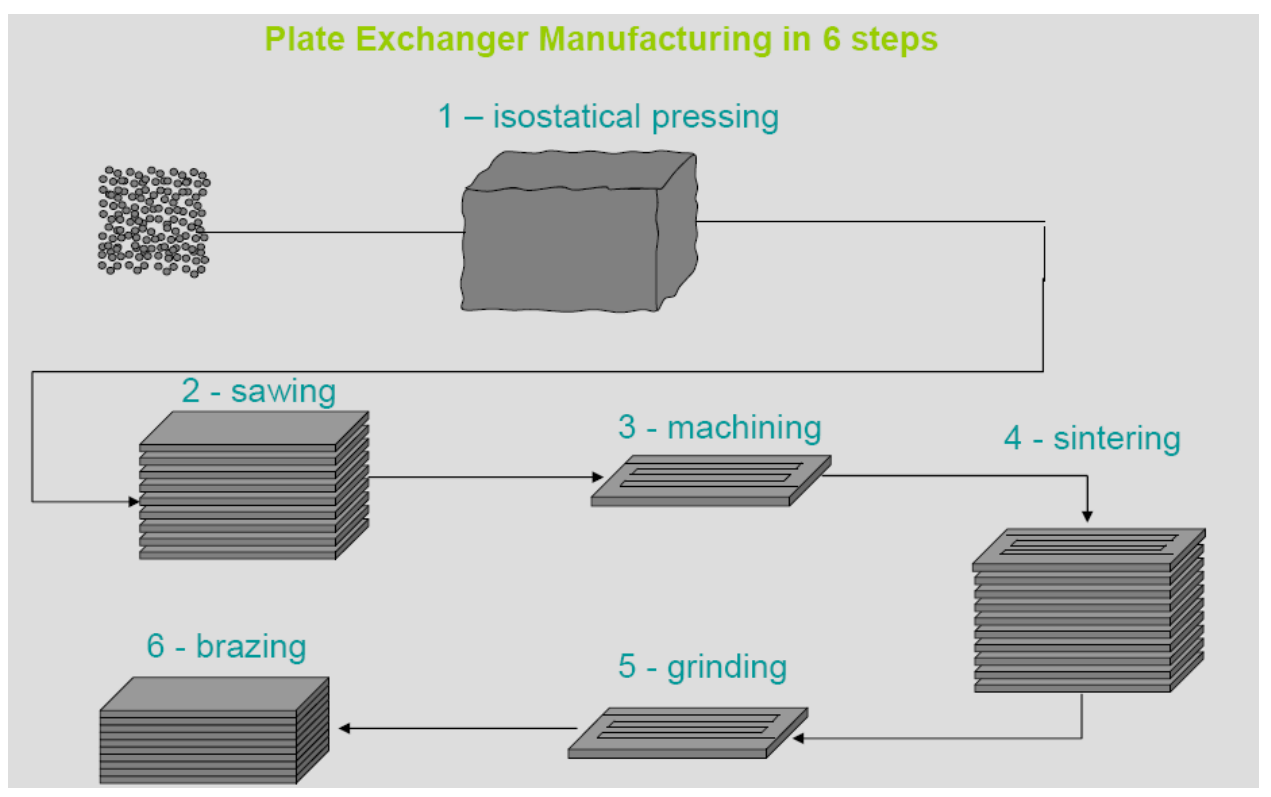

While the multiple adiabatic reactor concept seems the most promising for the decomposer, building and testing of an elementary mock-up is not planned as it can not be readily scaled down to manufacture suitable prototype.

At this first step, the limiting process step is most probably the sealing at all junctions - whether fixed or removable for catalyst regeneration. The current activities concentrate on this aspect by studying two different joining techniques, based on different brazing alloys and brazing processes. Thus, mock-ups of design concept a) and b) are being manufactured by the partners CEA and Boostec applying the mentioned techniques. This way allows focusing on the greatest technological challenge. The individual steps involved in fabricating the prototype are depicted in Figure 5.

\subsection{Solar receiver-reactors as $\mathrm{H}_{2} \mathrm{SO}_{4}$ decomposer}

A prototype receiver-reactor for solar decomposition of sulphuric acid has been designed and simulated and will be subsequently tested in DLR's solar furnace in cologne to prove the feasibility of the concept, to investigate the process behaviour, and to refine available experimental data for design studies and for process simulation. The development of a multi-chamber reactor (Figure 6) is of central interest in order to separately examine the vaporisation and $\mathrm{SO}_{3}$ reduction processes. The core parts of both chambers are porous $\mathrm{SiC}$ ceramics serving on the one hand as absorbers for concentrated solar radiation and on the other hand as reactive zone. One chamber contains a ceramic foam which is wetted by sulphuric acid. Heat is transferred from the hot surface of the foam to the liquid to vaporise it and to provide the feed for the second chamber. This second chamber contains a ceramic honeycomb structure (optionally) coated by a catalyst and heated to 
temperature above $800^{\circ} \mathrm{C}$ by concentrated sunlight to enable the reduction of $\mathrm{SO}_{3}$. This setup allows the independent optimisation of the two process steps.

Figure 6 Design of the solar two-chamber $\mathrm{H}_{2} \mathrm{SO}_{4}$ decomposer (see online version for colours)
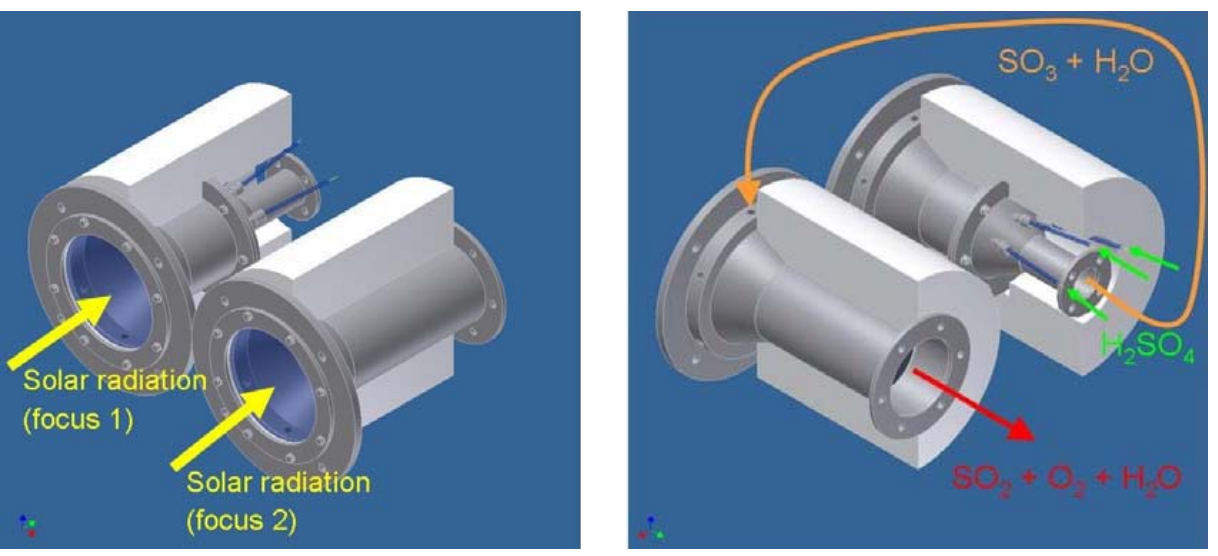

Figure 7 Thermal stresses simulated by FEM ( $\mathrm{Pa})$ (see online version for colours)

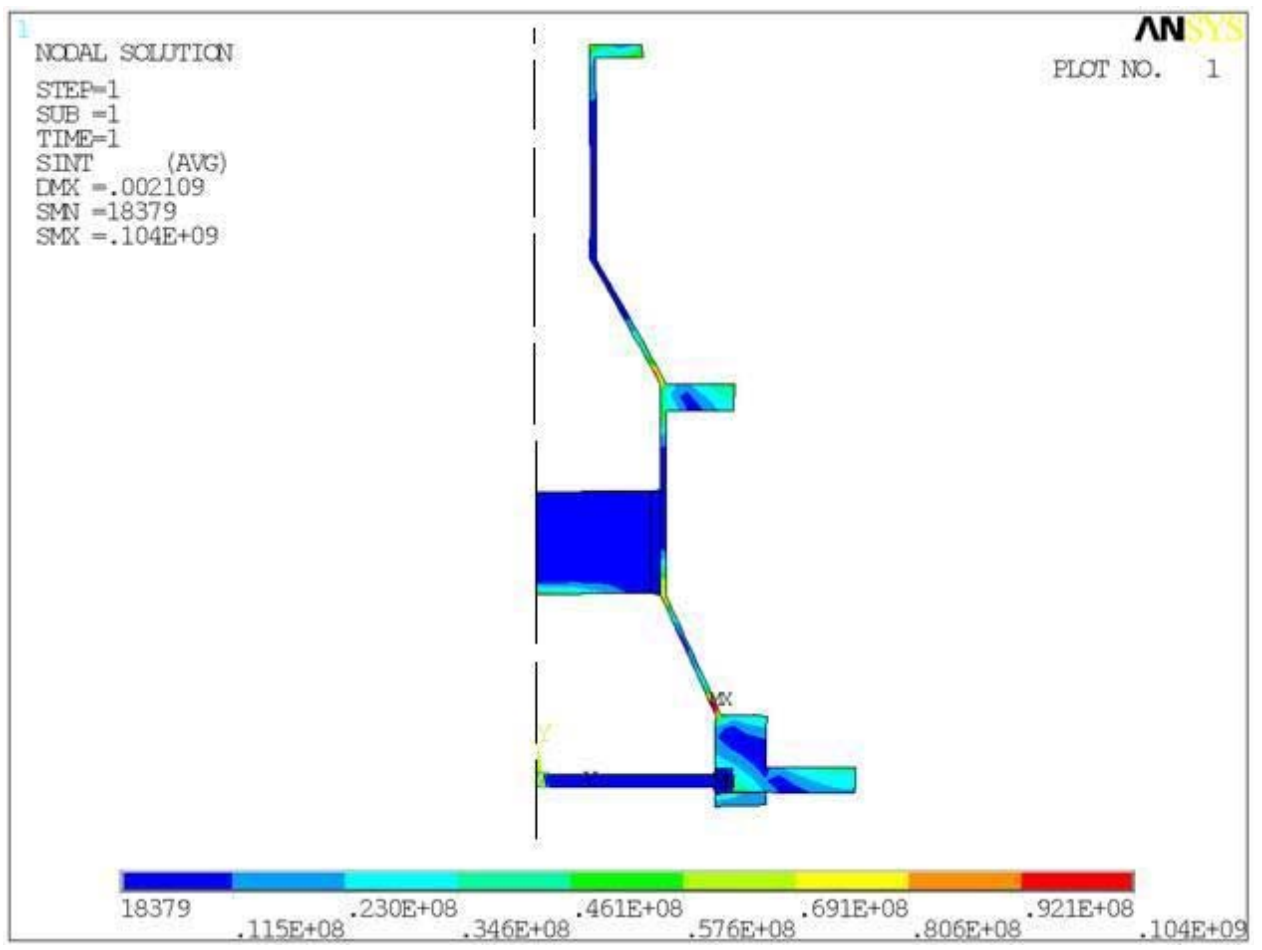

The thermo-structural integrity of the planned reactor has been evaluated and predicted by FEM-modelling to enable the finalisation and proof of the design. The temperatures of all components are within the tolerated range of the materials, while the reactor's thermal behaviour assures good temperature distribution and heat transfer. From the structural 
point of view no high stresses or deformations were foreseen (Figure7) and the model has proved that the stress levels for each component is below their allowable limits and that the deformations can be absorbed without problems. The reactor design has proved to be consistent with the requested conditions on steady state operation.

The results of the simulation were also used to complete the final design, which is finished now being the starting-point of the construction. Experiments in the solar furnace and continuing simulations will go hand in hand to converge in the optimal values for the parameters such as focal plane location, range of solar power, ceramic foam and honeycomb dimensions and characteristics. Eventually, this interplay between experiment and simulation will assist in achieving a better understanding of the whole chemical process.

Due to its importance the absorber structure as a core part of the receiver-reactor has been analysed in depth. In the case of the evaporator this absorber is a so-called reticulate porous ceramic (RPC). The ceramic foam is directly exposed to concentrated solar energy and serves as the radiation absorber and heat transfer medium to the reacting fluid for the evaporation and thermal decomposition of $\mathrm{H}_{2} \mathrm{SO}_{4}$. Accurate knowledge of its effective heat/mass transport properties is crucial for process simulation and subsequent optimisation regarding the design and operation of the solar reactor. The structure and dimensions of the porous ceramic must enable efficient evaporation while avoiding reduced heat transfer at the Leidenfrost point. Computer tomography (CT) in conjunction with numerical techniques have been used to determine the morphological characteristics and the effective heat/mass transfer properties of the foam, such as extinction coefficient, scattering function, thermal conductivity, interfacial heat transfer coefficient, permeability, Dupuit-Forchheimer coefficient, tortuosity and residence time distributions, and dispersion tensor. CT combined with numerical techniques enables accurate determination of the effective foam properties since the complex structure is accurately incorporated in the calculations. The effective conductivity of the foam as a function of the intrinsic solid/fluid conductivities is shown in Figure 8 and compared to models approximating the effective conductivity in a serial or parallel slab material with the same porosity $\varepsilon$ as the foam ( $k_{e}$ : effective conductivity, $k_{f}$ : conductivity of the fluid, $k_{s}$ : conductivity of the solid). It exemplary demonstrates the importance of the material's morphology on the effective material properties.

CSIRO have considerable experience in the design and operation of tubular reformers, originally developed for the solar driven steam reforming of methane. The reactor concept features a tube in tube design where the inner tube transports the initially cool feed stream to the high temperature reaction zone, which sits in a cavity irradiated by concentrated solar energy (see Figure 9). The reforming reaction is conducted in a catalyst packed bed in the annulus between the inner and outer tubes. The counter current flow enables heat exchange between the hot and cold fluid streams to improve heat integration of the process. One of the activities to be conducted in HycycleS will be to determine if this reactor concept is suitable for the decomposition of $\mathrm{H}_{2} \mathrm{SO}_{4}$. CSIRO intends to develop a CFD model of the methane reforming reactor in FLUENT, which can then be used to examine the behaviour of the $\mathrm{H}_{2} \mathrm{SO}_{4}$ system. 
Figure 8 Effective thermal conductivity of the foam and of parallel and serial slabs at $\varepsilon=0.91$

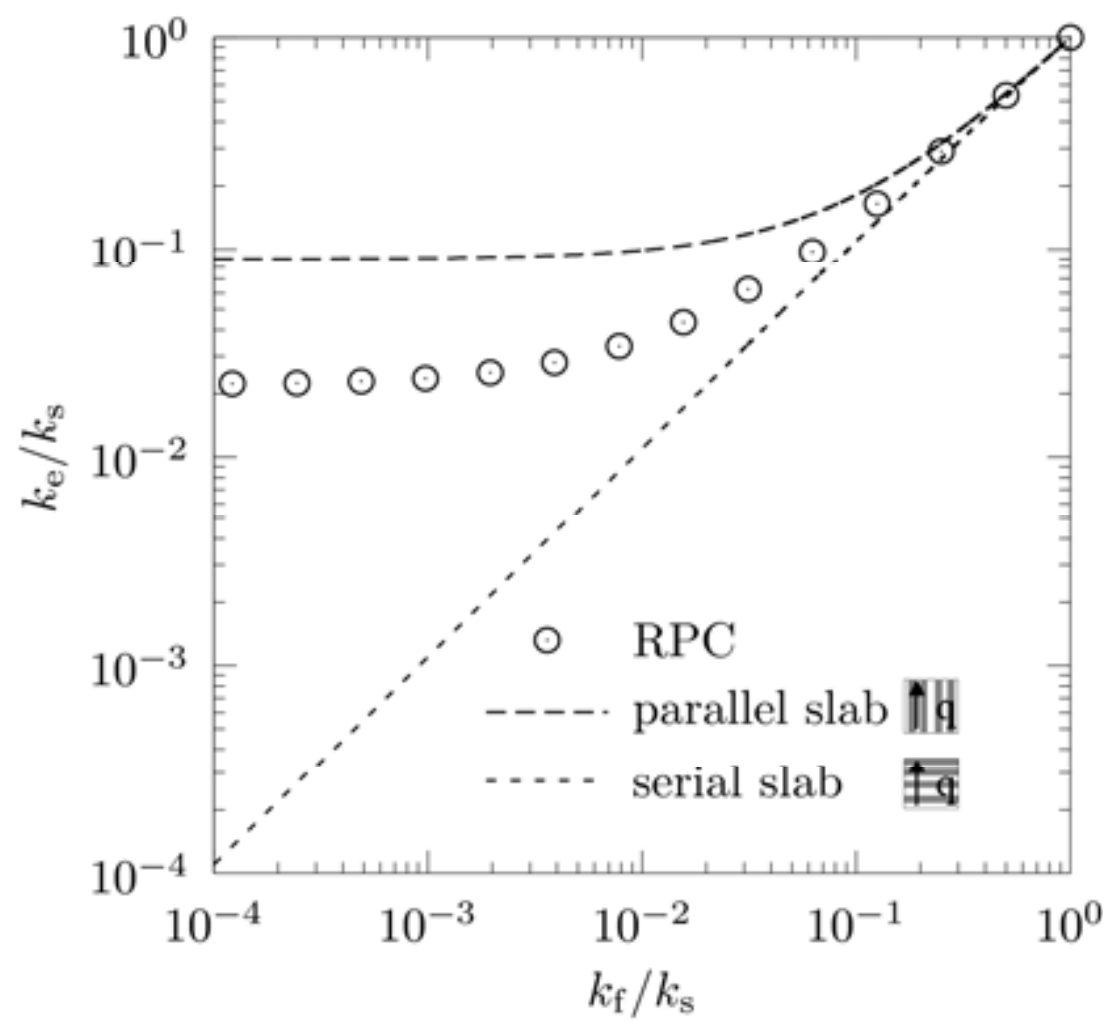

Figure 9 Indirectly irradiated tubular reactor at CSIRO in Newcastle, Australia (see online version for colours)
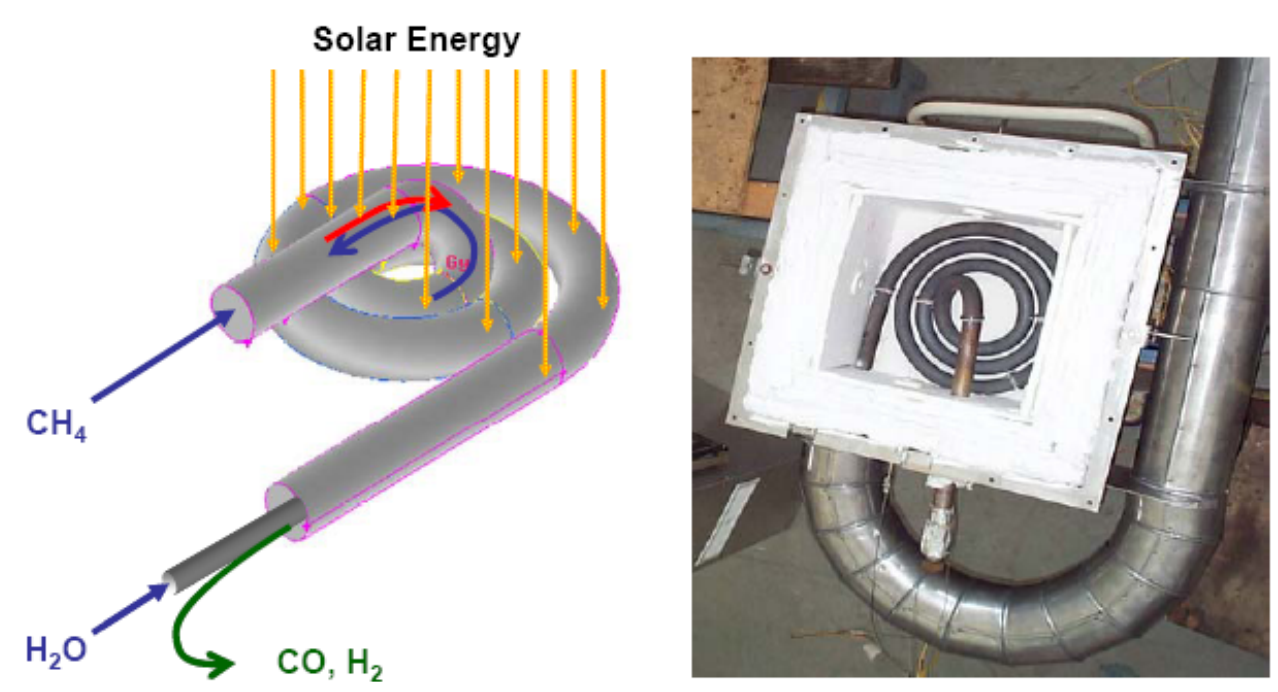
Tubular reactors rated for up to $20 \mathrm{bar}$ and $950^{\circ} \mathrm{C}$ are currently available from projects on solar steam reforming of methane. These reactors need to be assessed to determine if they are also suitable for $\mathrm{SO}_{3}$ decomposition. CSIRO operates several potential test beds for the reactor including a $30 \mathrm{~kW}$ electric furnace and (up to) $500 \mathrm{~kW}$ heliostat field as possible heat sources. Experimental work with volumetric and tubular receiver-reactors may be included in a common study evaluating the feasibility of the technology at a commercial scale. CSIRO has also been conducting process simulations of the HyS process to examine some of the process integration issues, and in a related study is assessing the reaction mechanisms and especially the role of the catalyst in the electrolytic oxidation of $\mathrm{SO}_{2}$ in $\mathrm{H}_{2} \mathrm{SO}_{4}$.

Figure 10 Overall schematic of Westinghouse composite reactor

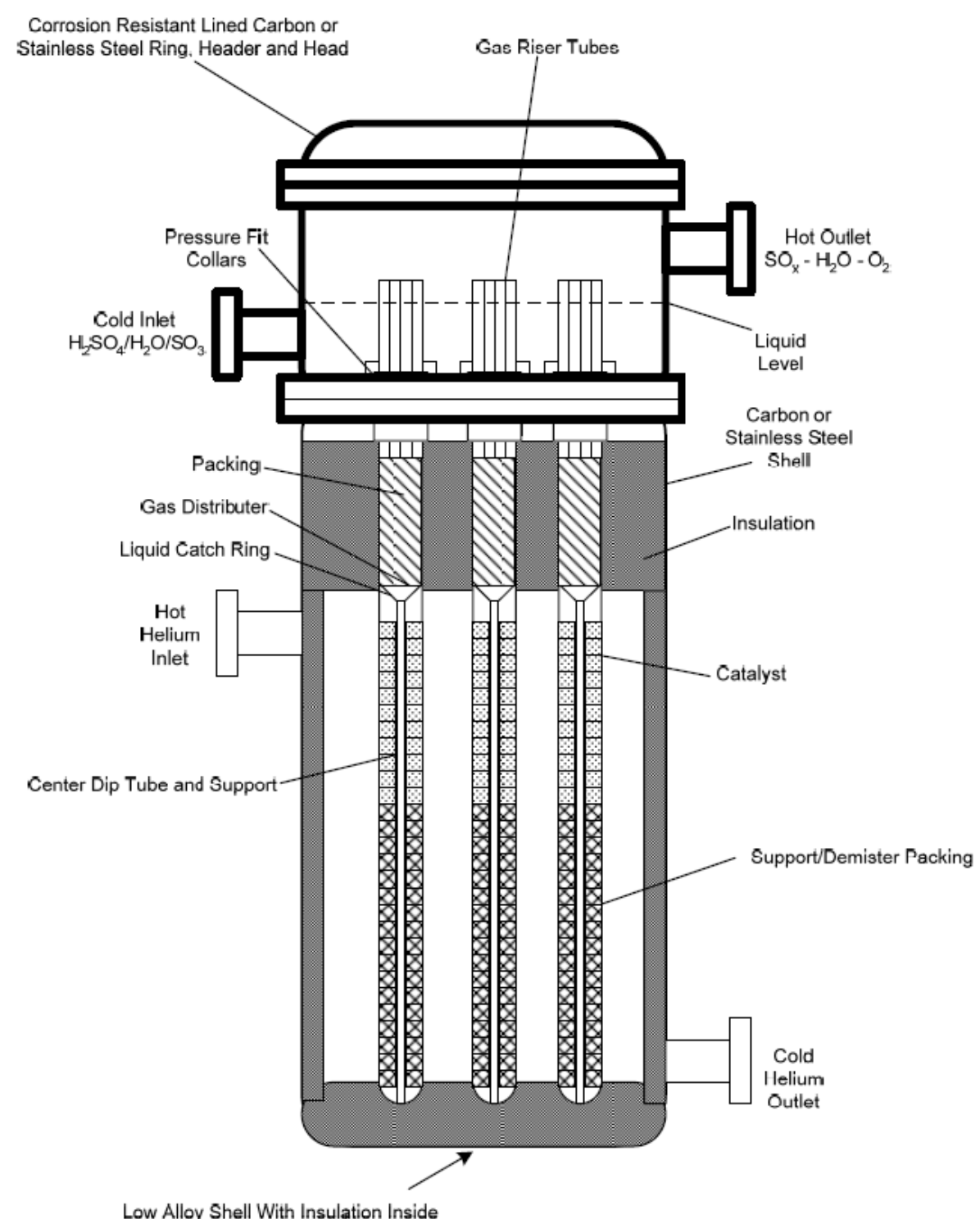


Figure 11 Detail of individual Westinghouse composite operation tube

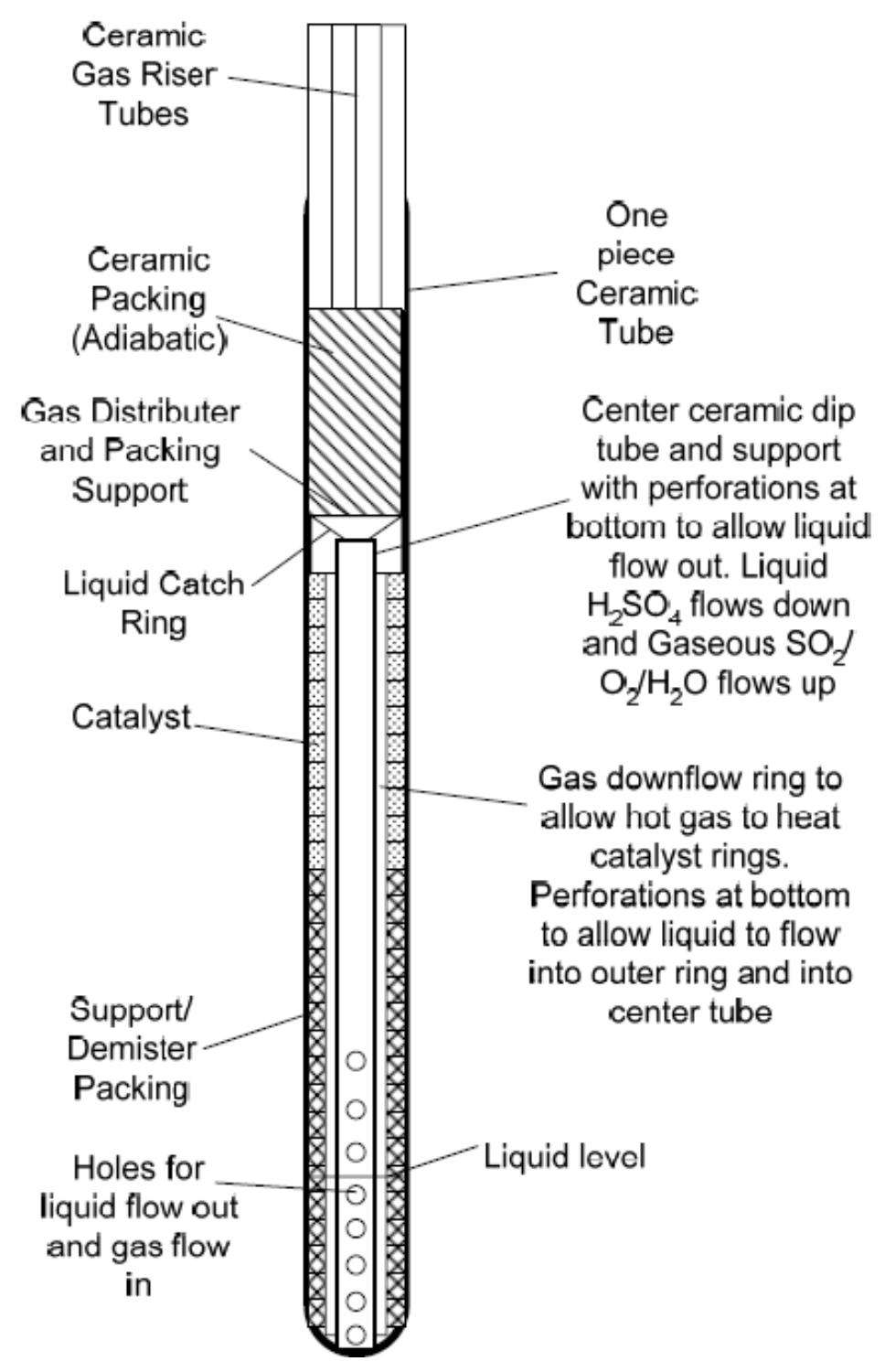

\subsection{Westinghouse sulphuric acid recuperative decomposition reactor design}

The Westinghouse decomposition reactor design is a top-fed, multi-step reactor that preheats, concentrates, and decomposes sulphuric acid. The reactor will operate under moderate pressure differentials $(<0.3 \mathrm{MPa})$ between the heated gas and liquid sides. $\mathrm{SiC}$ is utilised for the high temperature and heat transfer portions of the reactor and Teflon lined metal in the low temperature distribution headers of the reactor. All seals are located in low temperature portions of the reactor, allowing for the use of Teflon or a similar material. A general schematic of the composite reactor is shown in Figure 10. The 
design allows for relatively low cost construction by using carbon or stainless steel for the pressure boundary of the vessel.

The decomposition tubes consist of a ceramic bayonet tube with an inside ceramic support tube, as shown in Figure 11. The bayonet tubes are contained in a vessel with internal insulation and structured packing to facilitate heat transfer from the helium to the bayonet tube.

Inside the bayonet tube, a double-walled insulated ceramic support tube sits on the bottom of the bayonet tube and supports a ceramic liquid catch ring with sloped sides and a hole in the middle. A ceramic gas distribution plate then sits on top of the liquid catch ring, which in turn supports ceramic packing material. On top of the packing material is a set of ceramic gas riser tubes filled with packing. At the bottom of the bayonet tube, ceramic packing material sits in the annulus between the bayonet and support tubes and supports a catalyst to be used in the decomposition reaction. The entire assembly is made of $\mathrm{SiC}$, and is handled as a single unit. The primary advantages to the Westinghouse design lay in its amenability to assembly, inspection, and maintenance as well as the requirement for only one seal location. Additionally, the seal is not under a hydrostatic head that could result in a $\mathrm{H}_{2} \mathrm{SO}_{4}$ leak into the helium side.

\section{Product separation}

The development of a high temperature oxygen separation membrane is a challenging objective which has the capacity to enable radical change in the decomposition reactor. This could come about either by reducing hold up and increasing yield, thereby making one of the most vulnerable and expensive high pressure components much smaller, or by lowering the maximum temperature of the process, thereby making it accessible to a wider range of heat sources. Oak Ridge National Laboratory have performed some preliminary work, reported in Forsberg (2003) and Forsberg et al. (2004). Their work was at lower temperatures with porous membranes. The present approach builds on the extensive international work that has been undertaken to develop solid oxide fuel cell (SOFC) membranes and uses dense membranes, such as doped yttria stabilised zirconia (YSZ) and lanthanum strontium manganate (LSM), which are only capable of conducting oxygen at very high temperature (Marazou et al., 2006; Badwal and Ciacchi, 2001). So far these materials havenot been tested under highly sulphating conditions although initial work performed has demonstrated that significant resistance to membrane degradation is probable. An oxygen separator unit using these principles has been considered by Dyer et al. (2000), working only on pure air at temperature up to $730^{\circ} \mathrm{C}$.

The method carried out in the project HycycleS for study of this separation will be dense oxygen transport membranes. This type of membrane, made from novel and complex ceramics, is currently being researched worldwide for use in SOFCs. The material properties are such that the membrane conducts only oxide ions and hence should exhibit a high separation factor for oxygen over the other components present in the process. This may enable a high purity oxygen stream to be produced without the need for a further oxygen separation step or a significant reduction of the needed splitting temperature.

A review of high temperature oxygen separation membrane materials, identified from previous work on fuel cells, has been undertaken. Very little data can be found in the literature on the resistance of these materials to the sulphuric acid decomposition 
products at the relevant process conditions. Two types of dense oxygen transport membrane material were identified as potential candidates:

- $\quad$ mixed ionic/electronic conductors (MIECs)

- electrically driven membranes.

MIECs are good conductors of both oxide ions and electrons. There is no external electron conduction path and oxygen transport is in the direction of high to low oxygen partial pressure, whilst electrons travel in the opposite direction. Potential MIEC materials include lanthanum silicates, lanthanum strontium manganites and ceria-based materials, although this list is not exhaustive. These MIEC materials are often doped with metals such as magnesium, manganese, strontium, gadolinium and aluminium in order to improve the properties for a given application.

In contrast, electrically driven dense membranes conduct oxygen ions when heated, but conduct electrons poorly. In order for the membrane to function, an external electron conduction path must be provided. This requirement is used to good effect in SOFCs in order to extract electrical power from an electrochemical cell using a membrane of this type as the electrolyte. Zirconia and YSZ are examples of ion conducting membranes.

Calculations were performed using HSC Chemistry to evaluate the process stability of candidate materials identified in the review. An example of the calculations is shown in Figure 12. Yttria and zirconia were both calculated to be stable in the temperature range of interest, except for zirconia at $<750^{\circ} \mathrm{C}$ and 20 bar. Because of this, YSZ is considered to be a good candidate material and is being investigated further. Based on the results of the equilibrium calculations, the majority of the metal oxides identified by the literature review are not suitable for use with a sulphuric acid thermal decomposition process.

Experimental stability and permeation testing of the membranes is carried out using a high temperature membrane cell held within a furnace. A photo of the experimental setup is shown in Figure 13.

The experimental program has recently started and focuses on oxygen permeability and its stability under relevant conditions.

Figure 12 An example of metal oxide/sulphate equilibrium calculated by HSC chemistry

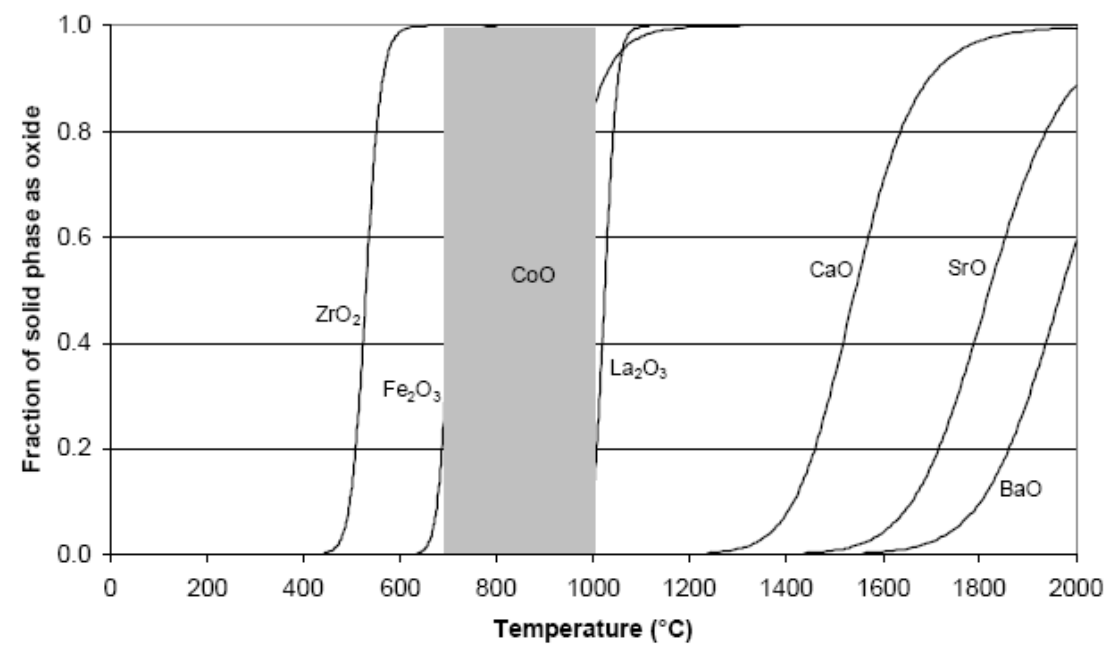


Figure 13 Experimental setup for high temperature membrane testing (see online version for colours)

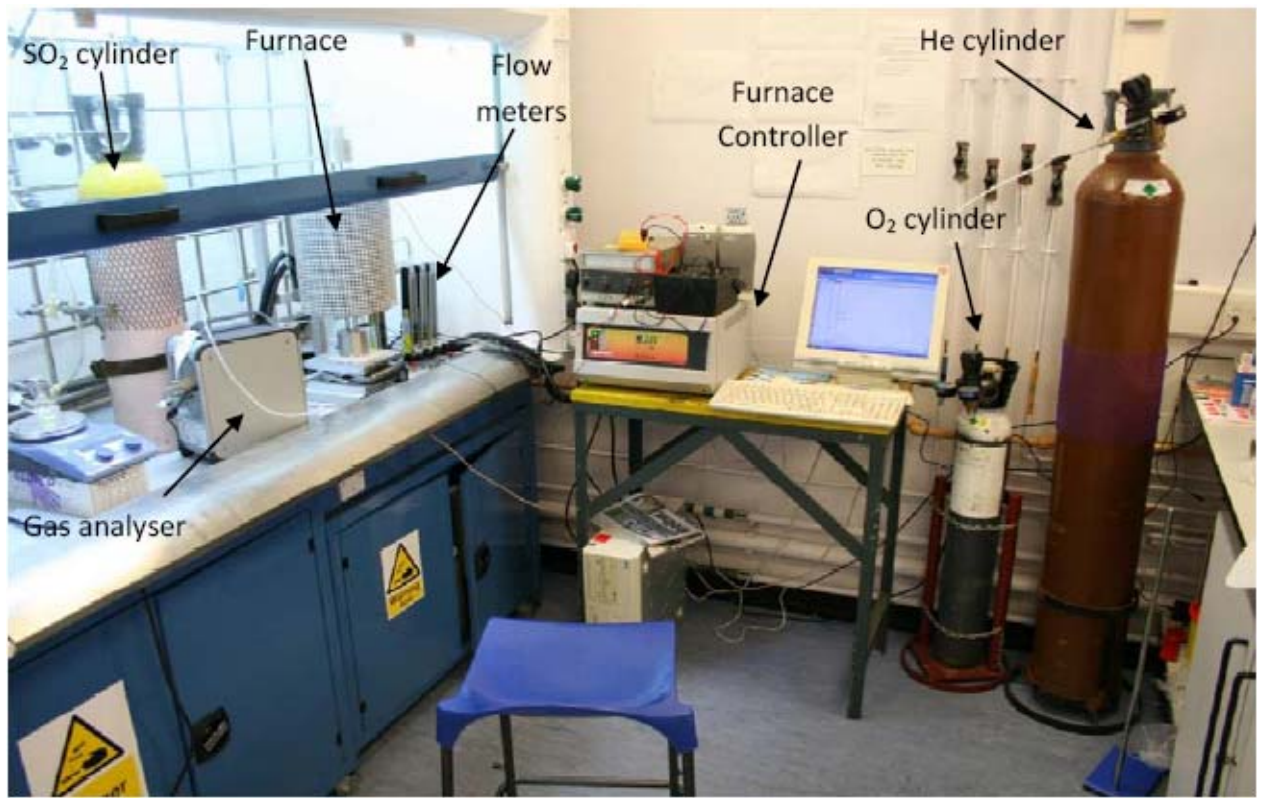

\section{Techno-economics}

Previous studies have shown that one of the main drivers for the investment costs of a hydrogen production plant is the component cost mainly based on the compulsory choice of very expensive materials (Gilardi et al., 2006). In the majority of cases these are the only ones which are able to withstand the extreme conditions of the sulphur-based thermochemical cycles. Alternatives of materials and component designs will be assessed in the plant evaluation.

HycycleS evaluates the impact of the key alternatives concerning the choice of materials, manufacturability, reliability etc. on investment cost and on the production cost of hydrogen. An analysis will be carried out to assess the critical aspects regarding component costs, reliability, maintenance that most strongly influence the hydrogen production cost.

At the moment, a general calculation method and a procedure of assessing the process have been agreed and a spreadsheet to collect all the necessary 'technical' input is already available. In the second part of the project the techno-economic model will be finalised and the model will be defined in detail. The results will be obtained after data for investment, operation and maintenance and also decommissioning have been determined. The basis of the plant layout and costing are the process flow sheets developed by DLR (solar coupling) and the CEA (nuclear coupling) and results concerning material choice and components' performance will be based on the experimental work carried out in HycycleS. 


\section{Summary}

The project HycycleS started early 2008. It has a core team of nine European partners and is additionally linked to activities currently conducted in the USA, Japan, and Australia. Therefore key partners from those countries are involved to ensure coordination of activities and information exchange with respect to sulphur-based cycles in the different continents as well as the definition of potential interfaces. Beyond that, HycycleS activities are strongly linked with international initiatives on hydrogen production to mutually benefit from different experiences.

The first year of the project started with a review on potential construction materials for the targeted key components of sulphur-based thermo-chemical cycles and on possible and promising catalyst/substrate combinations for the catalytic high temperature reduction of $\mathrm{SO}_{3}$ as one of the crucial steps of the process.

As a consequence of this review, the main development route for HycycleS is based on ceramic materials from the $\mathrm{SiC}$ family - for both the solar absorbers of the planned receiver reactor as also for the plates of the planned compact heat exchanger. Base materials for oxygen separation membranes will be YSZ.

Requirement specifications were set up as a basis for design and sizing of the intended prototypes and mock-ups. Test rigs for different purposes - corrosion tests, catalyst development, catalyst stability tests, selectivity of separation membranes - have been designed, built and completed. Prototypes have been designed.

Next steps will concentrate on the refinement of component and material testing and of catalyst screening and in particular on the construction and testing of prototypes.

\section{Acknowledgements}

The authors acknowledge the co-funding of the European Commission for the FP7 project HycycleS (Contract-No. 212470).

\section{References}

Badwal, S. and Ciacchi, F. (2001) 'Ceramic membrane technologies for oxygen separation', A.I.Che. E.J., Vol. 51, No. 6, pp.1582-1589.

Barbarossa, V., Brunetti, B., Brutti, S., Diamanti, M., Sau, S. and De Maria, G. (2005) 'Sulfuric acid decomposition using solar energy: a preliminarily experimental study', 2nd European Hydrogen Energy Conference, November, Zaragoza, Spain.

Barbarossa, V., Brutti, S., Diamanti, M., Sau, S. and De Maria, G. (2006) 'Catalytic thermal decomposition of sulfuric acid in sulfur-iodine cycle for hydrogen production', International Journal of Hydrogen Energy, Vol. 31, p.883.

Barbarossa, V., Diamanti, M. and Visentin, V. (2004) 'An experimental and numerical study on $\mathrm{H}_{2} \mathrm{SO}_{4}$ thermal decomposition', Chemical Engineering Transactions, Vol. 4, p.223.

Beghi, G.E. (1986) 'A decade of research on thermochemical hydrogen at the joint research centre', Int. J. of Hydrogen Energy, Vol. 11, pp.761-771, ISPRA.

Brecher, L.E., Spewock, S. and Warde, C.J. (1976) 'The Westinghouse sulfur cycle for the thermochemical decomposition of water', in Nejat Veziroglu, T. (Ed.): Proc. 1st World Hydrogen Energy Conference, Vol. 1, pp.9A-1-9A-16H, Miami Beach Florida.

Brutti, S., Bencivenni, L., Barbarossa, V., Sau, S. and De Maria, G. (2006) 'Gas phase dissociation of $\mathrm{H}_{2} \mathrm{SO}_{4}$ : A computational study', J. Chem. Thermodynamics, Vol. 38, p.1292. 
Connolly, S.M., Zabolotny, E., McLaughlin, D.F. and Lahoda, E.J. (2007) Design of composite sulfuric acid decomposition reactor, concentrator and preheater for hydrogen generation processes, AIChEE Annual Meeting 2007, November, Saltlake City, USA.

Dyer, P. et al. (2000) 'Ion transport membrane technology for oxygen separation and syngas production', Solid State Ionics, Vol. 134, Nos. 1-2, p.21.

Forsberg, C. (2003) 'A lower temperature iodine Westinghouse-ispra sulfur process for thermochemical production of hydrogen', American Nuclear Society Winter Meeting, ORNL, New Orleans, USA.

Forsberg, C. et al. (2004) 'Sulfur thermochemical processes with inorganic membranes to produce hydrogen', AIChE Spring National Meeting, ORNL, New Orleans, USA.

Gelbard, F., Andazola, J.C., Naranjo, G.E., Velasquez, C.E. and Reay, A.R. (2005) High Pressure Sulfuric Acid Decomposition Experiments for the Sulfur-Iodine Thermochemical Cycle, September, SANDIA REPORT SAND2005-5598.

General Atomics (1985) Decomposition of Sulfuric Acid Using Solar Thermal Energy, General Atomics report, GA-A-17573.

Gilardi, T., Rodriguez, G., Gomez, A., Leybros, J., Borgard, J.M., Carles, P. and Anzieu, P. (2006) 'Influence of material choice on cost estimation of some key components of the sulfur iodine thermochemical process', Proc. of 16th World Hydrogen Energy Conference (WHEC), Lyon, France, 13-16 June.

Ginosar, D.M. et al. (2007) 'Stability of supported platinum sulfuric acid decomposition catalysts for use in thermochemical water splitting cycles', International J. of Hydrogen Energy, Vol. 32, pp.482-488.

Jung, K-D. et al. (2006) decomposition of sulfuric acid to produce sulfur dioxide and oxygen in is cycle, Presentation at AIChE Conference, 12-17 November, San Francisco, USA.

Le Duigou, A. et al. (2007) 'HYTHEC: an EC funded search for a long term massive hydrogen production route using solar and nuclear technologies', International Journal of Hydrogen Energy, Vol. 32, pp.1516-1529.

Lewinsohn, C. et al. (2006) 'High temperature ceramic heat exchanger material', UNLV/DOE NHI Review, 25 July, available at http://nstg.nevada.edu/heatexchangers1.html.

Marazou, I. et al. (2006) 'Electronic conductivity, oxygen permeability and thermal expansion of $\mathrm{SR}_{0.7} \mathrm{Ce}_{0.3} \mathrm{Mn}_{1-\mathrm{x}} \mathrm{AlxO}_{3-\delta}$, Journal of the European Ceramic Society, Vol. 26, No. 8, pp.1371-1378.

Noglik, A. et al. (2007) 'Development of a solar receiver-reactor for decomposition of sulfuric acid', Presentation at GVC-VDI meeting 'Energieverfahrenstechnik' und 'Biokraftstoffe', 26-27 February, Würzburg, Germany.

Noglik, A., Roeb, M., Rzepczyk, T., Hinkley, J., Sattler, C. and Pitz-Paal, R. (2009) 'Solar thermochemical generation of hydrogen: development of a receiver reactor for the decomposition of sulfuric acid', J. of Solar Energy Engineering, February, p.131.

Norman, J.H., Besenbruch, G.E., Brown, L.C., O'Keefe, D.R. and Allen, C.L. (1982) Thermochemical Water-Splitting Cycle, Bench-Scale Investigations and Process Engineering, DOE Report DOE/ET/26225-1.

O'Keefe, D.R. et al. (1980) 'Catalyst Research in thermochemical water splitting processes', Catal. Rev. Sci. Eng., Vol. 22, No. 3, pp.325-369.

Roeb, M. et al. (2006) 'Thermo-chemical production of hydrogen from water by metal oxides fixed on ceramic substrates', 16th World Hydrogen Energy Conference (WHEC), 13-16 June, Lyon, France.

Terada, A. et al. (2006) Development of Sulfuric Acid Decomposer for Thermochemical Hydrogen Production IS Process, Vol. 5, No. 1, pp.68-75, Nippon Genshiryoku Gakkai Wabun Ronbunshi.

Wong, B. et al. (2007) Corrosion and Crack Growth Studies of HX Construction Materials for HI Decomposition, IFT/P2006-063, available at http://nstg.nevada.edu/heatexchangers1.html. 